\section{Expressed emotion: a cross-culturally valid}

\section{concept $?^{\dagger}$}

\author{
ANDREW T. A. CHENG
}

Since the introduction of the concept of expressed emotion (EE) (Brown et al, 1962, 1972), that is emotion expressed by close relatives towards a family member with schizophrenia, there have been several studies focusing on its influence on the course of schizophrenia and other disorders. Although most studies have supported the hypothesis that high EE predicts relapse of schizophrenia, a few good quality studies have failed to do so (e.g. MacMillan et al, 1986, 1987). A recent investigation using meta-analysis of data from $27 \mathrm{EE}$ studies reported a significant association between high EE and schizophrenia relapse (Butzlaff \& Hooley, 1998). However, the studies included were largely from Western countries, all of them were cross-sectional, and problems regarding the cross-cultural validity of assessments of EE were not discussed.

A number of relevant issues have been raised over the years, including the role of $\mathrm{EE}$ as a trait (that exists among relatives of patients before the onset of the disorder) or state (that occurs among relatives in reaction to the onset of the disorder); the frequency of patients' contact with their relatives before a relapse; the timing of $\mathrm{EE}$ assessment (before or during a relapse); the stability of EE levels over time; differential EE levels among relatives living with the patient; potential confounding/interacting effects on EE level and the course of the disorder of socio-demographic factors, social support, life events, medication and psychosocial treatment; cross-cultural validity of the concept and assessment of EE (Jenkins \& Karno, 1992; Kavanagh, 1992). The cross-cultural validity of EE has been examined in a few non-Western cultures, with controversial findings. Interestingly, a recent study in China, although it failed to find a significant association between high EE and relapse of schizophrenia (Phillips \& Xiong, 1995),

†See pp. 488-493, this issue. demonstrated a significant contribution of high EE to the level of stigma (Phillips et al, 2002, this issue).

\section{IS THE STUDY OF EE AN ETIC PHENOMENON?}

The original concept of EE includes a set of positive and negative emotions, among which three major negative components criticism, hostility and emotional overinvolvement - have become the focus of research in both Western and non-Western countries. It has been pointed out, however, that what counts as criticism, hostility and emotional overinvolvement is a matter of cultural definition (Jenkins \& Karno, 1992). Culture determines whether any type of EE is a prominent part of the emotional response among family members, the specific content/target of various EE components, and factors influencing their levels. It follows that the study of EE should have both etic and emic characteristics. For example, the frequency and intensity of individual types of EE varies widely across cultures, with the proportion of high EE among relatives of individuals with schizophrenia defined by the Western operational criteria ranging from $8 \%$ in rural India (Wig et al, 1987b) to $67 \%$ in urban USA (Vaughn et al, 1984).

\section{EE AS ILLNESS BEHAVIOUR ACROSS CULTURES}

The finding that a very low proportion $(4 \%)$ of the relatives of people with schizophrenia in the Indian study was rated high in emotional overinvolvement was attributed to issues of interrater reliability resulting from training problems (Wig et al, 1987a). A corresponding figure of $17.5 \%$ was reported in China, which fell to $7.0 \%$ when the cut-off point of measurement of emotional overinvolvement was raised from 3 to 4 (Phillips \& Xiong, 1995). The authors commented that the Western criteria for high emotional overinvolvement were inappropriate in Chinese culture, where most unmarried persons with schizophrenia stay with their parents. This may bring about much more contact between patients and their parents, leading to greater exposure to EE in Chinese and other non-Western societies than in their Western counterparts. The implications of such differential exposure to EE may deserve further enquiry.

Previous work in psychological anthropology has observed that Chinese families are parent-child dominated, rather than husband-wife dominated as observed in Western societies (Hsu, 1973). Unlike the Western family, in which the autonomy and independence of children are stressed, in the Chinese family children's obedience and acceptance of parents' criticism, and interdependence between generations, are encouraged. The sick role played by a Chinese person with schizophrenia and the family's response has certain emic characteristics (Lin \& Lin, 1980). It is therefore likely that the norms of various components of EE among Chinese relatives of patients with schizophrenia, and perhaps also among relatives in other cultures dominated by extended families (El-Islam, 1982), are considerably different from those among their Western counterparts. The evidence does indicate that the distribution and mean scores of criticism, hostility and emotional involvement are significantly different across cultures (Leff \& Vaughn, 1985). Possibly other components of EE, in addition to criticism, hostility and emotional overinvolvement, merit examination and comparison between different cultures.

\section{MEASUREMENT OF EE ACROSS CULTURES}

The measurement of EE has commonly applied the 90-min Camberwell Family Interview (CFI) (Brown \& Rutter, 1966) for individual relatives, and the degree of EE has been rated according to operational criteria (Vaughn \& Leff, 1976).

Since the evidence has indicated a cross-cultural difference regarding the level of tolerance among family members towards the person with schizophrenia, it is likely that patients' perception of and coping with different levels of EE differ cross-culturally. Therefore, EE assessment 
has to be re-calibrated in different cultures. Furthermore, raters assessing EE in different cultures might be influenced by their own non-Western cultural backgrounds. These issues require cross-cultural validity and interrater reliability studies, in which researchers from different cultures together might observe, using CFI interviews, and rate EE of relatives from different cultures. This could be followed by a thorough discussion of any differences in content, meaning, expression and cultural norms of any EE observed by any rater. In so doing, emic bias in the interviewer or the interviewee could be optimally resolved, including the different expressiveness of patients and family members across cultures. For example, relatives in some cultures might mask their negative attitude and emotional responses in front of interviewers (Phillips \& Xiong, 1995). Such a strategy, which requires adequate financial support and staffing, has recently been applied in the assessment of psychopathology using the Schedules for Clinical Assessment in Neuropsychiatry (SCAN), with considerable progress (Cheng et al, 2001). Similarly, the possible influence on EE assessment of differences in the frequency of contact between patients and relatives, as well as types of relatives, should be taken into account.

\section{CONCLUSIONS}

Research in EE and mental disorder could be more useful if studies of the crosscultural validity, the reliability and the general methodological issues of $\mathrm{EE}$ assessment were carried out longitudinally across cultures.

ANDREW T. A. CHENG, FRCPsych, Institute of Biomedical Sciences, Academia Sinica, Taipei, Taiwan. Fax: 017I-277 0283; e-mail: bmandrew@ccvax.sinica.edu.tw

(First received 25 March 2002, final revision 5 July 2002, accepted 5 September 2002)

\section{REFERENCES}

Brown, G.W. \& Rutter, M. (1966) The measurement of family activities and relationships: methodological study. Human Relations, 19, 241-263.

\section{—, Monck, E. M., Carstairs, G. M., et al (1962)}

Influences of family life on the course of schizophrenic illness. British Journal of Preventive and Social Medicine, 16, 55-68.

_ , Birley, J. L. \& Wing, J. K. (1972) Influence of family life on the course of schizophrenic disorders: a replication. British journal of Psychiatry, I2I, 24I-258.

Butzlaff, R. L. \& Hooley, J. M. (1998) Expressed emotion and psychiatric relapse. Archives of General Psychiatry, 55, 547-552.

Cheng, A. T. A., Tien, A. Y., Chang, C. J., et al (2001) Cross-cultural implementation of a Chinese version of the Schedules for Clinical Assessment in

Neuropsychiatry (SCAN) in Taiwan. British journal of Psychiatry, 178, 567-572.

El-Islam, M. F. (1982) Rehabilitation of schizophrenics by the extended family. Acta Psychiatrica Scandinavica, 65, $112-119$.

Hsu, F. L. K. (1973) Kinship is the key. The Center Magazine, II(6), 4-14.

Jenkins, J. H. \& Karno, M. (1992) The meaning of expressed emotion: theoretical issues raised by crosscultural research. American Journal of Psychiatry, 149, 9-21.

Kavanagh, D. J. (1992) Recent developments in expressed emotion and schizophrenia. British Journal of Psychiatry, 160, 601-620.

Leff, J. \& Vaughn, C. (1985) Expressed Emotion in Families: Its Significance for Mental Illness. New York: Guilford Press.

Lin, T.Y. \& Lin, M. C. (1980) Love, denial and rejection: responses of Chinese families to mental illness. In Normal and Abnormal Behavior in Chinese Culture (eds
A. Kleinman \& T. Y. Lin), pp. 387-40I. Boston, MA: D. Reidel.

MacMillan, J. F., Gold, A., Crow, T. J., et al (1986) The Northwick Park study of first episodes of schizophrenia. IV. Expressed emotion and relapse. British Journal of Psychiatry, 148, 133-143.

_ , Crow, T. J., Johnson, A. L., et al (1987) Expressed emotion and relapse in first episodes of schizophrenia. British Journal of Psychiatry, I5I, 320-323.

Phillips, M. R. \& Xiong, W. (1995) Expressed emotion in mainland China: Chinese families with schizophrenic patients. International Journal of Mental Health, 24, 54-75.

_, Pearson, V., Li, F., et al (2002) Stigma and expressed emotion: a study of people with schizophrenia and their family members in China. British Journal of Psychiatry, I8I, 488-493.

Vaughn, C. E. \& Leff, J. (1976) The measurement of expressed emotion in the families of psychiatric patients. British Journal of Social and Clinical Psychology, 15, 157-165.

_, Snyder, K. S., Jones, S., et al (1984) Family factors in schizophrenic relapse: replication in California of British research on expressed emotion. Archives of General Psychiatry, 4I, II69-1177.

Wig, N. N., Menon, D. K., Bedi, H., et al (1987a) Expressed emotion and schizophrenia in north India. I: Cross-cultural transfer of ratings of relatives' expressed emotion. British Journal of Psychiatry, I5I, 156-160.

_ , _ , _ , et al (1987b) Expressed emotion and schizophrenia in north India. II: Distribution of expressed emotion components among relatives of schizophrenic patients in Aarhus and Chandigarh. British Journal of Psychiatry, I5I, 160-165. 